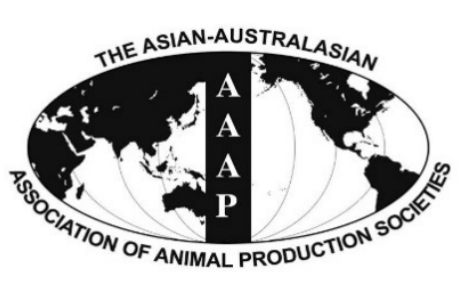

\begin{tabular}{c} 
Open Access \\
$\begin{array}{c}\text { Asian Australas. J. Anim. Sci. } \\
\text { Vol. 29, No. } 4 \text { : 555-563 April } 2016 \\
\text { http://dx.doi.org/10.5713/ajas.15.0396 }\end{array}$ \\
\hline www.ajas.info \\
pISSN 1011-2367 elSSN 1976-5517
\end{tabular}

\title{
Effects of Feeding Purple Rice (Oryza sativa L. Var. Glutinosa) on the Quality of Pork and Pork Products
}

\author{
Sanchai Jaturasitha*, Punnares Ratanapradit ${ }^{1}$, Witapong Piawong ${ }^{2}$, and Michael Kreuzer ${ }^{3}$ \\ Department of Animal and Aquatic Sciences, Faculty of Agriculture, \\ Chiang Mai University, Chiang Mai 50200, Thailand
}

\begin{abstract}
Purple rice is a strain of glutaneous rice rich in anthocyanins and $\gamma$-oryzanol. Both types of compounds are involved in antioxidant and lipid metabolism of mammals. Three experimental diet types were used which consisted approximately by half either of purple rice, white rice or corn. Diets were fed to $3 \times 10$ pigs growing from about 30 to $100 \mathrm{~kg}$. Meat samples were investigated either as raw or cured loin chops or as smoked bacon produced from the belly. Various physicochemical traits were assessed and data were evaluated by analysis of variance. Traits describing water-holding capacity (drip, thaw, and cooking losses) and tenderness (sensory grading, shear force) of the meat were mostly not significantly affected by the diet type. However, purple rice feeding of pigs resulted in lower fat and cholesterol contents of loin and smoked bacon compared to white rice, but not compared to corn feeding except of the fat content of the loin. The shelf life of the raw loin chops was improved by purple rice as well. In detail, the occurrence of thiobarbituric acid reactive substances after 9 days of chilled storage was three to four times higher in the white rice and corn diets than with purple rice. The n-6:n-3 ratio in the raw loin chops was 9:1 with purple rice and clearly higher with 12:1 with the other diets, meat lipids. Level and kind of effect of purple rice found in raw meat was not always recovered in the cured loin chops and the smoked bacon. Still the impression of flavor and color, as well as overall acceptability were best in the smoked bacon from the purple-rice fed pigs, whereas this effect did not occur in the cured loin chops. These findings suggest that purple rice has a certain, useful, bioactivity in pigs concerning meat quality, but some of these effects are of low practical relevance. Further studies have to show ways how transiency and low recovery in meat products of some of the effects can be counteracted. (Key Words: Pig, Rice, Loin, Bacon, Anthocyanin, Antioxidant Properties)
\end{abstract}

\section{INTRODUCTION}

Purple rice (Oryza saitva L. var. glutinosa) is an indigenous Thai glutaneous rice strain characterized by purple pigments in the husk and the pericarp. The color is determined by a number of distinct anthocyanins (El-Sayed et al., 2006). These compounds are sub-elements of the

\footnotetext{
* Corresponding Author: Sanchai Jaturasitha. Tel: +66-53944001, Fax: +66-53944666, E-mail: ja.sanchai@gmail.com

${ }^{1}$ Faculty of Agricultural and Food Technology, Pibulsongkram Rajabhat University, Phitsanulok, 65000, Thailand.

2 Agricultural Extension Office, Ministry of Agriculture and Cooperative, Thunghuachang, Lamphun, 51160, Thailand.

${ }^{3}$ ETH Zurich, Institute of Agricultural Sciences, Universitaetstrasse 2, 8092 Zurich, Switzerland.

Submitted May 5, 2015; Revised Jul. 18, 2015; Accepted Aug. 24, 2015
}

proanthocyanidins and a phenolic compound. Anthocyanins are resistant against free radicals, especially when being in the form of cyanidin-3-glucosides (Nelida et al., 1998). Proanthocyanidins and cyanidin-3-glucosides are presumed to have a potential for reducing the risk of cardiovascular diseases and preventing lung cancer (Chen et al., 2006). A further compound of interest in purple rice is $\gamma$-oryzanol, which is part of the rice bran oil. Also present in rice in general, Boonsit et al. (2006) found that purple rice contains more $\gamma$-oryzanol than white rice. This compound was described to have favorable effects by reducing plasma triglycerides and low-density lipoprotein cholesterol in rats (Chen and Cheng, 2006) and increasing high-density lipoprotein cholesterol in hamsters (Wilson et al., 2007) as well as improving the immune response in mice (Teltathum, 2004). Teltathum (2004) noted that feeding purple rice bran 
increased the number of villi in the small intestine of mice which would facilitate nutrient absorption. Feeding purple rice instead of white rice and corn lowered total plasma cholesterol in fattening, though only at certain time points during fattening (Peawong et al., 2011). Overall, these properties of purple rice indicate that there might be also direct or indirect effects on the quality of the meat from pigs.

The objective of the present study was to test whether feeding purple rice to pigs improves the quality of meat and meat products. This improvement was expected to especially concern lipid-related properties like oxidative stability and sensory properties. Control diets were based on similar amounts of common rice and corn. The purple rice test diet was shown before to be equivalent to the white rice and corn diets in feeding value (Peawong et al., 2011) which excludes an otherwise possible bias in the results by a different growth rate. The meat samples used were also processed to meat products for the present investigation.

\section{MATERIALS AND METHODS}

\section{Animals and diets}

Thirty Duroc $\times($ Large White $\times$ Landrace $)$ crossbred piglets (barrows:gilts, 1:1) were randomly assigned to three isocaloric and isonitrogenous diets at $30 \mathrm{~kg}$ body weight in a complete randomized design. They were housed in individual pens of a size of $1.5 \times 2.0 \mathrm{~m}$ for on average of 11 weeks until they approached the target slaughter weight of $100 \mathrm{~kg}$. Treatments either consisted of a control diet based on corn and a certain amount of cassava chips as sources of starch, or of diets containing white rice, or purple rice. In the latter two diets, rice made up about $50 \%$ to $55 \%$ (depending on stage of fattening) and completely replaced corn and most of the cassava chips (Table 1). Starter, grower and finisher diets were offered at ad libitum access. Drinking water was provided by nipples. This experiment was approved by the Animal Care and Use Committee of the Thai Livestock Department and fulfilled international guiding principles (Council for International Organizations of Medical Sciences and the International Council for Laboratory Animal Science, 2012).

\section{Sample collection and processing}

Prior to slaughter, pigs were fasted for $12 \mathrm{~h}$, then transported for $7 \mathrm{~km}$ to the abattoir of the National Meat Technology and Training Centre, Chiang Mai, Thailand, and let rest for $2 \mathrm{~h}$. On two slaughter days, half of the pigs per treatment were slaughtered in a randomized order. After chilling for $24 \mathrm{~h}$ at $3^{\circ} \mathrm{C}$, the Longissimus thoracis of the left carcass side was harvested from the 6 th to the 14 th rib and cut into slices of $2.54 \mathrm{~cm}$ thickness. Slices were retained for color and weight loss measurements. The remaining raw loin chops were vacuum-packaged and stored at $-20^{\circ} \mathrm{C}$. The entire Longissimus thoracis et lumborum of right carcass side was prepared to be processed following the recipe for producing cured loin chops according to the German 'Kassler Rippchen' style. The entire belly of the right carcass side was harvested to be processed to smoked bacon. The methods for preparation of cured loin chops and the smoked bacon were based on standard recipes written down by the Thai Department of Livestock Development (2002). Meat of sizes of about $20 \mathrm{~cm} \times 30 \mathrm{~cm}$ was trimmed off skin and bones. The same brine was used for curing loin chops and bacon. It contained ( $\%$ of aqueous solution): ice water, 89.33, nitrite cure salt (mixture of $\mathrm{NaCl}$ and $\mathrm{NaNO}_{2}$,

Table 1. Ingredient composition of the experimental diets (\%) characterized by corn $(\mathrm{M})$, white rice (W), and purple rice (P) designed for the starting (30 to $50 \mathrm{~kg}$ body weight), growing ( 50 to $80 \mathrm{~kg}$ ) and finishing ( 80 to $100 \mathrm{~kg}$ ) periods, respectively

\begin{tabular}{|c|c|c|c|c|c|c|c|c|c|}
\hline & \multicolumn{3}{|c|}{ Starting period } & \multicolumn{3}{|c|}{ Growing period } & \multicolumn{3}{|c|}{ Finishing period } \\
\hline & $\mathrm{M}$ & $\mathrm{W}$ & $\mathrm{P}$ & $\mathrm{M}$ & $\mathrm{W}$ & $\mathrm{P}$ & $\mathrm{M}$ & $\mathrm{W}$ & $\mathrm{P}$ \\
\hline Corn & 46.8 & 0 & 0 & 50 & 0 & 0 & 54.2 & 0 & 0 \\
\hline White broken rice & 0 & 50 & 0 & 0 & 53.2 & 0 & 0 & 55 & 0 \\
\hline Purple broken rice & 0 & 0 & 50 & 0 & 0 & 53.2 & 0 & 0 & 55 \\
\hline Cassava chips & 14.5 & 1 & 1 & 15.9 & 1 & 1 & 16 & 1.4 & 1.4 \\
\hline Bran from white rice & 1 & 14 & 14 & 1 & 15.7 & 15.7 & 1 & 17 & 17 \\
\hline Soybean meal & 27.5 & 24.8 & 24.8 & 24 & 21 & 21 & 23 & 22 & 22 \\
\hline Palm oil & 3 & 3 & 3 & 2.3 & 2.1 & 2.1 & 0.2 & 0 & 0 \\
\hline Fish meal & 5 & 5 & 5 & 4.8 & 5 & 5 & 3 & 2 & 2 \\
\hline Dicalcium phosphate & 0.9 & 0.9 & 0.9 & 0.7 & 0.7 & 0.7 & 0.5 & 0.5 & 0.5 \\
\hline Limestone & 0.7 & 0.7 & 0.7 & 0.7 & 0.7 & 0.7 & 0.7 & 0.7 & 0.7 \\
\hline $\mathrm{NaCl}$ & 0.35 & 0.35 & 0.35 & 0.35 & 0.35 & 0.35 & 0.35 & 0.35 & 0.35 \\
\hline Vitamin-mineral premix ${ }^{1}$ & 0.25 & 0.25 & 0.25 & 0.25 & 0.25 & 0.25 & 0.25 & 0.25 & 0.25 \\
\hline Lysine & 0 & 0 & 0 & 0 & 0 & 0 & 0.8 & 0.8 & 0.8 \\
\hline
\end{tabular}

${ }^{1}$ Contained per kg of feed: Ca, $332.5 \mathrm{mg}$; Fe, $60 \mathrm{mg}$; Se, $0.08 \mathrm{mg}$; Mn, $50 \mathrm{mg}$; Zn, $80 \mathrm{mg}$; Co, $0.16 \mathrm{mg}$; Cu, $100 \mathrm{mg}$; I, 0.05 g; vitamin A, 8,000 IU; vitamin $\mathrm{D}_{3}, 1,000 \mathrm{IU}$; vitamin $\mathrm{E}, 10 \mathrm{mg}$; vitamin $\mathrm{K}_{3}, 1 \mathrm{mg}$; vitamin $\mathrm{B}_{1}, 1 \mathrm{mg}$; vitamin $\mathrm{B}_{2}, 2 \mathrm{mg}$; vitamin $\mathrm{B}_{6}, 1.5 \mathrm{mg}$; vitamin $\mathrm{B}_{12}$, $0.01 \mathrm{mg}$; pantothenic acid, $8 \mathrm{mg}$; niacin, $10 \mathrm{mg}$; choline chloride, $75 \mathrm{mg}$; biotin $0.03 \mathrm{mg}$. 
0.96:0.04 w/w), 4.07; sugar, 2.77; phosphate, 2.77; monosodium glutamate, 0.58 ; sodium erythorbate, 0.23 ; milk protein, 0.11; smoke powder, 0.13 . The cold brine $\left(2^{\circ} \mathrm{C}\right)$ was injected at a level equivalent 0.1 of the meat's weight. Then the treated meat was allowed to equilibrate for $24 \mathrm{~h}$ at $4^{\circ} \mathrm{C}$, carefully washed with water and hung to let liquid drip off. Subsequently, bacons were dried without smoking in the smoking chamber for $30 \mathrm{~min}$, followed by smoking for $3 \mathrm{~h}$, both at $70^{\circ} \mathrm{C}$. The cured loin chops and the bacons were cut into $1-\mathrm{cm}$ and $3-\mathrm{mm}$ thick slices, respectively, and stored at $-20^{\circ} \mathrm{C}$.

\section{Laboratory analyses}

The finisher diets were analyzed for proximate contents applying methods from AOAC (2005). The fatty acid (FA) profile was determined after extraction and transformation to FA methyl esters with the same method and gas chromatograph as described in detail below for FA in the meat. Total phenol contents of the diets were determined by a modified Folin-Ciocalteu method (Makkar, 2003) using a UV-Vis spectrophotometer (Shimadzu UV-160, Shimadzu Corporation, Kyoto, Japan). Values were calibrated against gallic acid (Sigma-Aldrich, Steinheim, Germany). Total anthocyanins were analyzed with HPLC (Waters Alliance 2690, Waters Corporation, Milford, MA, USA) equipped with UV-Vis detector using cyanidine-3-O-glycosidechloride as a standard (X Terra MS C18, $5 \mu \mathrm{m}, 250 \times 4.6 \mathrm{~mm}$ column, Waters) by following the method of Pharmacopée Francaise (1996).

Raw loin chops were put into sealed bags at $24 \mathrm{~h} \mathrm{pm}$ and stored at $4^{\circ} \mathrm{C}$ for $48 \mathrm{~h}$, followed by blooming in the refrigerator without bag for $1 \mathrm{~h}$. Then the color $\left(\mathrm{L}^{*}, \mathrm{a}^{*}, \mathrm{~b}^{*}\right)$ was measured with a Chroma Meter (Minolta, CR-300, Osaka, Japan). Other raw loin chops were subjected to drip loss measurements. Thaw and grilling (convection oven, model 720 , Mara, Taipei, Taiwan at $150^{\circ} \mathrm{C}$ up to $70^{\circ} \mathrm{C}$ internal temperature) losses were recorded in raw and cured loin chops, and in the smoked bacon. In addition, raw loin chops were cooked in sealed plastic bags in a water bath to $70^{\circ} \mathrm{C}$. They were allowed to cool at $25^{\circ} \mathrm{C}$ before being subjected to shear force measurements. Cores $(1.27 \mathrm{~cm}$ diameter) were sheared perpendicular to muscle fiber direction with a Warner-Bratzler shear blade (texture analyzer, model TA.XT plus, Stable Micro System, London, UK). A crosshead speed of $200 \mathrm{~mm} / \mathrm{min}$ and a $5 \mathrm{kN}$ load cell calibrated to read over a range of 0 to $100 \mathrm{~N}$ were applied.

Samples of raw loin chops and smoked bacon were minced and analyzed in duplicate for contents of moisture, protein (Kjeldahl; $6.25 \times \mathrm{N}$ ) and fat (AOAC, 2005). Cholesterol was determined colorimetrically with a photometer at a wavelength of $560 \mathrm{~nm}$ in samples first extracted by petroleum ether followed by saponification with alcoholic KOH (Bohac et al., 1998). Soluble, insoluble and total collagen was assessed in the raw loin chops following Hill (1989). For that, $4 \mathrm{~g}$ meat sample was homogenized with $8 \mathrm{~mL}$ of strength Ringer solution and then boiled in water bath at $77^{\circ} \mathrm{C}$ for $70 \mathrm{~min}$. Centrifugation at $5,200 \mathrm{~g}$ for $26 \mathrm{~min}$ was followed by separation into supernatant and natant. This was followed by hydrolysis $(30$ $\left.\mathrm{mL} \mathrm{H}_{2} \mathrm{SO}_{4}\right)$, drying $\left(105^{\circ} \mathrm{C}, 16 \mathrm{~h}\right)$, transferring contents to $500 \mathrm{~mL}$ flasks, and adjusting volume to $500 \mathrm{~mL}$ by distilled water (AOAC, 1996). The solutions were subjected to spectrometer analysis at $558 \mathrm{~nm}$ (UV 1601, Shimadzu, Tokyo, Japan) to determine hydroxyproline. Soluble collagen was calculated as $7.52 \times$ hydroxyproline in the supernatant, whereas insoluble collagen was set to $7.25 \times$ hydroxyproline in the natant.

Fatty acids in raw loin chops and smoked bacon were analyzed according to Raes et al. (2001). First they were extracted by a mixture of chloroform and methanol (Folch et al., 1957). The FA methyl esters were prepared according to Morrison and Smith (1964). Gas chromatographic analysis was accomplished with model GC-14B of Shimadzu (Kyoto, Japan) equipped with a $0.25 \mathrm{~mm} \times 30 \mathrm{~m} \times 0.25 \mu \mathrm{m}$ wall-coated fused silica capillary column (SP2560, Supelco Inc., Bellefonte, PA, USA, coated with cyanopropyl polysiloxane stationary phase). The carrier gas was helium. Oven temperature programming included an increase from $50^{\circ} \mathrm{C}$ to $220^{\circ} \mathrm{C}$ at a rate of $10^{\circ} \mathrm{C} / \mathrm{min}$, held for $35 \mathrm{~min}$, up from $200^{\circ} \mathrm{C}$ to $230^{\circ} \mathrm{C}$ at a rate of $5^{\circ} \mathrm{C} / \mathrm{min}$ and then held at $230^{\circ} \mathrm{C}$ for $20 \mathrm{~min}$. Injector and detector temperatures were $250^{\circ} \mathrm{C}$. Chromatograms were processed by the Millenium 2010 Chromatography Manager (Millipore Corp., Milford, MA, USA). Identification was accomplished by comparing the retention time of peaks from samples with those of FAME standard mixtures. Quantification of FAME was based on the internal standard technique, using margaric acid (17:0) as internal standard and on the conversion of relative peak areas into weight percentages, using the corrected response factor of each FA (ES ISO 5508, 1990). Fatty acids were expressed as gravimetric contents (mg/100 g meat).

The 2-thiobarbituric acid (TBARS, thiobarbituric acid reactive substances) method (Rossel, 1994) was applied to raw loin chops, cured loin chops and smoked bacon. Briefly, $10 \mathrm{~g}$ of sample, stored for $0,3,6$, and 9 days at $4^{\circ} \mathrm{C}$, were mixed with $30 \mathrm{~mL}$ distilled water for $2 \mathrm{~min}$ by a Moulinex household blender. Then $65 \mathrm{~mL}$ of distilled water was added, the $\mathrm{pH}$ was adjusted to 1.44 with $2.5 \mathrm{~mL}$ of $4 \mathrm{M} \mathrm{HCl}$ and drops of antifoaming agent were added. An amount of $50 \mathrm{~mL}$ of distillate from this was collected within 15 to 20 min whereof $5 \mathrm{~mL}$ were allowed to react with $5 \mathrm{~mL}$ of TBA reagent. The absorbance was measured in the cooled solution against a blank at $538 \mathrm{~nm}$. Absorbance $\times 7.8$ was defined as TBARS. Results were given as concentrations of 
mg malondialdehyde/kg meat.

For sensory analysis, raw and cured loin chops as well as smoked bacon were wrapped in aluminum foil and cooked to $70^{\circ} \mathrm{C}$ in a convection oven pre-heated at $200^{\circ} \mathrm{C}$. A sensory panel comprising nine trained members rated the samples using standard procedures outlined by AMSA (1995). Descriptors evaluated were firmness, flavor, juiciness, tenderness, odor, color and overall acceptability using a nine-point scale ranging from $1=$ dislike extremely to $9=$ like extremely.

\section{Statistical analysis}

Data was subjected to mono-factorial analysis of variance using SAS (version 8.2, SAS Institute Inc., Cary, NC, USA). Comparisons among means were done by Duncan's Multiple Range Test. The tables give arithmetic means, standard errors of the mean (SEM) and p-values.

\section{RESULTS}

\section{Diet composition}

The analyzed nutrient composition was similar across finishing diets (Table 2). This was also true for individual FA and estimated metabolizable energy content. As anticipated, the purple rice diet was the only one with significant contents of anthocyanins and was richest in total phenols, followed by the white rice diet.

\section{Quality of raw and processed meat}

The meat was redder in the white rice group than in the other groups $(p<0.05)$. With rice in general the meat was

Table 2. Analyzed chemical composition of the finisher diets and estimated energy contents

\begin{tabular}{lccc}
\hline Diet type & Corn & $\begin{array}{c}\text { White } \\
\text { rice }\end{array}$ & $\begin{array}{c}\text { Purple } \\
\text { rice }\end{array}$ \\
\hline Crude protein (\% of dry matter (DM)) & 17.6 & 17.4 & 17.4 \\
Neutral detergent fiber (\% of DM) & 4.01 & 3.92 & 4.10 \\
Ether extract (\% of DM) & 5.42 & 5.27 & 5.48 \\
Fatty acids (\% of all FA analyzed) & & & \\
C16:0 & 22.4 & 22.3 & 21.1 \\
C18:0 & 2.34 & 2.25 & 2.27 \\
C18:1 & 26.9 & 26.1 & 25.2 \\
C18:2n-6 & 40.7 & 41.0 & 42.8 \\
C18:3n-3 & 2.71 & 2.59 & 2.69 \\
Saturated fatty acids & 27.2 & 27.9 & 26.8 \\
Monounsaturated fatty acids & 28.3 & 27.5 & 26.5 \\
Polyunsaturated fatty acids & 44.5 & 44.6 & 46.6 \\
n-6:n-3 fatty acid ratio & 14.9 & 15.7 & 15.8 \\
Anthocyanins (\% of DM) & 0.007 & ND & 0.073 \\
Total phenols (\% of DM) & 0.25 & 0.42 & 0.67 \\
Metabolizable energy (MJ/kg DM) ${ }^{1}$ & 15.0 & 15.1 & 15.1 \\
\hline DM, dry matter; FA, fatty acid; ND, not detected. & & \\
${ }^{1}$ Calculated from NRC (1998) feed tables. & & &
\end{tabular}

more yellow $(p<0.05)$ than with corn (Table 3$)$. Waterholding capacity measured as drip loss (only raw loin chops), thaw loss and grilling loss (both including cured loin chops and smoked bacon) did not differ among treatments. Similarly, shear force and collagen traits of the raw loin chops were not significantly affected. Moisture contents of raw loin chops and smoked bacon were unaffected by treatment, but the values of the smoked bacon were much lower than those of the raw loin chops due to heat treatment and higher fat content. Contents of protein and fat of the raw loin chops were highest $(p<0.05)$ with white rice, and intramuscular fat (IMF) content was lowest

Table 3. Physicochemical properties of raw loin chops and processed pork

\begin{tabular}{lccccc}
\hline Diet type & Corn & $\begin{array}{c}\text { White } \\
\text { rice }\end{array}$ & $\begin{array}{c}\text { Purple } \\
\text { rice }\end{array}$ & SEM & p-value \\
\hline Color (raw loin chops) & & & & & \\
L* (brightness) & 54.7 & 53.5 & 53.3 & 2.25 & 0.89 \\
$\mathrm{a}^{*}$ (redness) & $6.13^{\mathrm{b}}$ & $6.83^{\mathrm{a}}$ & $6.03^{\mathrm{b}}$ & 0.485 & 0.049 \\
$\mathrm{~b}^{*}$ (yellowness) & $8.72^{\mathrm{b}}$ & $9.82^{\mathrm{a}}$ & $9.52^{\mathrm{a}}$ & 0.621 & 0.016
\end{tabular}

Water-holding capacity (substance loss, \%)

Raw loin chops

$\begin{array}{lccccc}\text { Drip loss } & 5.16 & 5.68 & 5.95 & 0.679 & 0.67 \\ \text { Thaw loss } & 15.6 & 15.2 & 16.0 & 0.87 & 0.77 \\ \text { Boiling loss } & 20.0 & 19.1 & 19.8 & 0.86 & 0.89 \\ \begin{array}{l}\text { Cured loin chops } \\ \text { Thaw loss }\end{array} & 4.79 & 5.75 & 5.84 & 0.919 & 0.36 \\ \text { Grilling loss } & 23.9 & 21.4 & 21.9 & 9.33 & 0.28 \\ \text { Smoked bacon } & & & & & \\ \quad \text { Thaw loss } & 8.93 & 9.02 & 8.94 & 4.209 & 0.99 \\ \text { Grilling loss } & 26.4 & 25.5 & 23.4 & 3.26 & 0.92\end{array}$

Shear values (raw loin chops)

Force, $\mathrm{N}$

Energy, J $\quad 1.83$

$\begin{array}{llll}75.7 & 73.0 & 5.68 & 0.56\end{array}$

Collagen (\%; raw loin chops)

Soluble $\quad 0.30$

Insoluble $\quad 1.01$

Total $\quad 1.31$

$\begin{array}{lll}1.86 & 1.84 & 0.009\end{array}$

0.17

Nutrient composition (\%)

Moisture

$\begin{array}{llllll}\text { Raw loin chops } \quad 73.4 & 73.0 & 73.3 & 0.13 & 0.25\end{array}$

$\begin{array}{llllll}\text { Smoked bacon } \quad 51.1 & 50.2 & 49.8 & 0.68 & 0.89\end{array}$

Protein

$\begin{array}{llllll}\text { Raw loin chops } \quad 20.1^{\mathrm{b}} & 21.1^{\mathrm{a}} & 20.5^{\mathrm{ab}} & 0.13 & 0.012\end{array}$

$\begin{array}{llllll}\text { Smoked bacon } & 14.1 & 13.8 & 14.2 & 0.85 & 0.94\end{array}$

Fat

Raw loin chops $\quad 1.84^{\mathrm{b}} \quad 2.10^{\mathrm{a}} \quad 1.67^{\mathrm{c}} \quad 0.006 \quad<0.001$

$\begin{array}{llllll}\text { Smoked bacon } \quad 30.2^{\mathrm{b}} & 32.9^{\mathrm{a}} & 30.0^{\mathrm{b}} & 1.43 & 0.036\end{array}$

Cholesterol ( $\mathrm{mg} / \mathrm{kg})$

$\begin{array}{llllll}\text { Raw loin chops } \quad 760^{\mathrm{ab}} & 844^{\mathrm{a}} & 699^{\mathrm{b}} & 5.1 & 0.030\end{array}$

$\begin{array}{llllll}\text { Smoked bacon } \quad 906^{\mathrm{b}} & 958^{\mathrm{a}} & 900^{\mathrm{b}} & 54.8 & 0.019\end{array}$

SEM, standard error of the mean ( $\mathrm{n}=10$, number of replicates).

${ }^{a-c}$ Within row, means without a common superscript differ $(p>0.05)$. 
$(p<0.05)$ with purple rice. These differences were exhibited less clearly in the smoked bacon, where still the white rice group had the highest fat content. The cholesterol contents of raw loin chops and smoked bacon were higher $(p<0.05)$ with the white rice diet compared to the corn and purple rice diets.

Diet type affected $(p<0.05)$ the proportions of the majority of the FA in the lipids of the raw loin chops (Table $4)$. The purple rice group had higher $(\mathrm{p}<0.05)$ proportions of 16:0 than the white rice group, of 16:1 than the corn group, and of 18:2n-6 and 20:5n-3 than both other groups. The IMF from the white rice group was highest $(p<0.05)$ in proportions of 18:0 and 22:6n-3, that of the corn group was highest $(p<0.05)$ in $18: 1$ and total monounsaturated FA. Polyunsaturated FA and total n-3 FA proportions were lowest with the corn diet. The n-6:n-3 ratio was lowest $(p<0.05)$ with the purple rice diet. The level of significance of the diet effects on FA profile was much lower in the smoked bacon. The only remaining effect was that on 16:0

Table 4. Fatty acid composition (\% of all fatty acids analyzed) of the lipids in raw loin chops and smoked bacon

\begin{tabular}{|c|c|c|c|c|c|}
\hline Diet type & Corn & $\begin{array}{l}\text { White } \\
\text { rice }\end{array}$ & $\begin{array}{c}\text { Purple } \\
\text { rice }\end{array}$ & SEM & p-value \\
\hline \multicolumn{6}{|l|}{ Raw loin chops } \\
\hline $16: 0$ & $32.7^{\mathrm{a}}$ & $28.7^{\mathrm{b}}$ & $30.8^{\mathrm{a}}$ & 1.22 & 0.001 \\
\hline 18:0 & $5.08^{\mathrm{b}}$ & $7.63^{\mathrm{a}}$ & $4.69^{b}$ & 1.805 & 0.040 \\
\hline $16: 1$ & $0.51^{\mathrm{b}}$ & $1.03^{\mathrm{a}}$ & $1.04^{\mathrm{a}}$ & 0.010 & 0.001 \\
\hline $18: 1$ & $43.1^{\mathrm{a}}$ & $36.4^{\mathrm{b}}$ & $38.9^{\mathrm{b}}$ & 3.70 & 0.001 \\
\hline $18: 2 n-6$ & $11.7^{\mathrm{c}}$ & $13.9^{\mathrm{b}}$ & $14.7^{\mathrm{a}}$ & 0.37 & 0.001 \\
\hline $18: 3 n-3$ & 0.37 & 0.43 & 0.38 & 0.003 & 0.15 \\
\hline $20: 5 n-3$ & $0.20^{\mathrm{b}}$ & $0.59^{\mathrm{ab}}$ & $0.78^{\mathrm{a}}$ & 0.069 & 0.047 \\
\hline $22: 6 n-3$ & $0.35^{\mathrm{b}}$ & $1.89^{\mathrm{a}}$ & $0.90^{\mathrm{ab}}$ & 0.376 & 0.026 \\
\hline$n-3$ & $1.22^{\mathrm{c}}$ & $1.44^{\mathrm{b}}$ & $1.99^{\mathrm{a}}$ & 0.073 & 0.001 \\
\hline n-6:n-3 ratio, $x: 1$ & $12.1^{\mathrm{a}}$ & $12.0^{\mathrm{a}}$ & $8.6^{\mathrm{b}}$ & 0.043 & 0.001 \\
\hline Saturated & 38.7 & 39.4 & 37.6 & 1.55 & 0.36 \\
\hline Monounsaturated & $46.0^{\mathrm{a}}$ & $39.7^{\mathrm{b}}$ & $42.3^{b}$ & 4.50 & 0.006 \\
\hline Polyunsaturated & $15.2^{\mathrm{b}}$ & $20.9^{\mathrm{a}}$ & $20.1^{\mathrm{a}}$ & 2.13 & 0.001 \\
\hline \multicolumn{6}{|l|}{ Smoked bacon ${ }^{1}$} \\
\hline $16: 0$ & $26.8^{\mathrm{a}}$ & $22.0^{\mathrm{b}}$ & $22.4^{\mathrm{b}}$ & 3.25 & 0.043 \\
\hline $18: 0$ & 13.8 & 15.7 & 15.7 & 7.90 & 0.78 \\
\hline $16: 1$ & 2.75 & 3.09 & 2.17 & 28.2 & 0.78 \\
\hline $18: 1$ & 35.0 & 39.1 & 38.5 & 7.87 & 0.37 \\
\hline $18: 2 n-6$ & 12.4 & 10.8 & 11.0 & 2.14 & 0.56 \\
\hline $18: 3 n-3$ & 2.12 & 1.89 & 2.25 & 0.114 & 0.63 \\
\hline $20: 5 n-3$ & 0.51 & 0.56 & 0.51 & 0.006 & 0.80 \\
\hline$n-3$ & 2.51 & 2.25 & 2.77 & 0.161 & 0.44 \\
\hline n-6:n- 3 ratio, $x: 1$ & 5.1 & 4.9 & 4.3 & 0.039 & 0.71 \\
\hline Saturated & 43.4 & 40.6 & 41.3 & 8.13 & 0.65 \\
\hline Monounsaturated & 39.3 & 43.6 & 42.6 & 8.22 & 0.37 \\
\hline Polyunsaturated & 17.3 & 15.8 & 16.1 & 2.55 & 0.67 \\
\hline
\end{tabular}

where, however, the difference between the white and purple rice diets had disappeared.

Lipid oxidation was influenced by diet type in the raw loin chops (Table 5). Across the storage period it was most pronounced with corn followed by white rice and lowest with purple rice $(p<0.05)$. In the cured loin chops, the order was opposite on Day 0 (i.e. directly after processing), but differences disappeared with storage time. Starting at an already high initial TBARS level no diet effects were found in the smoked bacon.

Firmness was perceived more favorable $(p<0.05)$ in the cooked unprocessed loin chops of the rice-fed pigs than in the corn-fed pigs, whereas juiciness, tenderness and overall acceptability were lower $(\mathrm{p}<0.05)$ in the white rice group (Table 6). However, in the smoked bacon a number of sensory traits were scored higher $(\mathrm{p}<0.05)$ with the purple rice diet compared to either the white rice diet (flavor and overall acceptability) or the corn diet (color). However, sensory grading of the cured loin chops revealed no significant diet type effects.

\section{DISCUSSION}

The aim of the present study was to test the effects of purple rice, characterized by specific plant secondary compounds, at otherwise similar nutrient and energy supply. According to the results of diet analysis this goal was achieved. The similarity in feeding value was additionally confirmed by the lack of substantial diet type effects on growth performance and on most carcass characteristics as described previously by Peawong et al. (2011). On average

Table 5. Development with storage time of the level of thiobarbituric reactive substances (TBARS; mg malondialdehyde $/ \mathrm{kg}$ ) in raw loin chops and processed meat

\begin{tabular}{lccccc}
\hline Diet type & Corn & $\begin{array}{c}\text { White } \\
\text { rice }\end{array}$ & $\begin{array}{c}\text { Purple } \\
\text { rice }\end{array}$ & SEM & p-value \\
\hline Raw loin chops & & & & & \\
$\quad$ Day 0 & $0.09^{\mathrm{a}}$ & $0.07^{\mathrm{b}}$ & $0.05^{\mathrm{b}}$ & 0.001 & 0.004 \\
Day 3 & $0.14^{\mathrm{a}}$ & $0.14^{\mathrm{a}}$ & $0.10^{\mathrm{b}}$ & 0.001 & 0.008 \\
Day 6 & $0.19^{\mathrm{a}}$ & $0.15^{\mathrm{b}}$ & $0.11^{\mathrm{b}}$ & 0.001 & $<0.001$ \\
Day 9 & $0.58^{\mathrm{a}}$ & $0.51^{\mathrm{a}}$ & $0.15^{\mathrm{b}}$ & 0.002 & $<0.001$ \\
Cured loin chops & & & & & \\
Day 0 & $0.07^{\mathrm{b}}$ & $0.13^{\mathrm{ab}}$ & $0.18^{\mathrm{a}}$ & 0.001 & 0.031 \\
Day 3 & 0.12 & 0.14 & 0.14 & 0.001 & 0.14 \\
Day 6 & 0.36 & 0.33 & 0.22 & 0.010 & 0.23 \\
Day 9 & 0.60 & 0.61 & 0.50 & 0.004 & 0.31 \\
Smoked bacon & & & & & \\
Day 0 & 1.12 & 1.19 & 0.96 & 0.086 & 0.82 \\
Day 3 & 1.21 & 1.56 & 1.27 & 0.022 & 0.33 \\
Day 6 & 1.55 & 1.59 & 1.52 & 0.113 & 0.99 \\
Day 9 & 1.56 & 1.67 & 1.54 & 0.025 & 0.79 \\
\hline
\end{tabular}

SEM, standard error of the mean $(n=10$, number of replicates).

a-b Within row, means without a common superscript differ $(\mathrm{p}>0.05)$. 
Table 6. Sensory grading ${ }^{1}$ of cooked meat and meat products

\begin{tabular}{|c|c|c|c|c|c|}
\hline Diet type & Corn & $\begin{array}{c}\text { White } \\
\text { rice }\end{array}$ & $\begin{array}{l}\text { Purple } \\
\text { rice }\end{array}$ & SEM & p-val \\
\hline \multicolumn{6}{|l|}{ Unprocessed loin chops } \\
\hline Firmness & $7.21^{\mathrm{b}}$ & $7.42^{\mathrm{a}}$ & $7.51^{\mathrm{a}}$ & 0.052 & 0.049 \\
\hline Flavor & 6.06 & 5.80 & 6.00 & 0.109 & 0.74 \\
\hline Juiciness & $5.47^{\mathrm{a}}$ & $3.83^{\mathrm{b}}$ & $5.61^{\mathrm{a}}$ & 0.098 & $<0.001$ \\
\hline Tenderness & $6.08^{\mathrm{a}}$ & $5.03^{\mathrm{b}}$ & $5.90^{\mathrm{a}}$ & 0.084 & $<0.001$ \\
\hline Overall acceptability & $6.26^{\mathrm{a}}$ & $5.82^{\mathrm{b}}$ & $6.11^{\mathrm{a}}$ & 0.089 & 0.048 \\
\hline \multicolumn{6}{|l|}{ Cured loin chops } \\
\hline Firmness & 7.44 & 7.47 & 7.50 & 0.022 & 0.25 \\
\hline Flavor & 6.36 & 6.72 & 6.36 & 0.060 & 0.31 \\
\hline Juiciness & 5.25 & 4.97 & 5.58 & 0.146 & 0.49 \\
\hline Tenderness & 6.06 & 6.00 & 6.36 & 0.155 & 0.51 \\
\hline Odor & 4.86 & 4.81 & 4.73 & 0.113 & 0.22 \\
\hline Color & 5.67 & 5.74 & 6.08 & 0.167 & 0.29 \\
\hline Overall accept & 6.33 & 6.50 & 6.78 & 0.067 & 0.37 \\
\hline \multicolumn{6}{|l|}{ Smoked bacon } \\
\hline Firmness & 7.36 & 7.11 & 7.33 & 0.009 & 0.90 \\
\hline Flavor & $6.97^{\mathrm{ab}}$ & $6.61^{\mathrm{b}}$ & $7.08^{\mathrm{a}}$ & 0.018 & 0.047 \\
\hline Juiciness & 5.86 & 6.17 & 5.83 & 0.041 & 0.42 \\
\hline Tenderness & 6.19 & 6.28 & 6.14 & 0.027 & 0.82 \\
\hline Odor & 4.86 & 4.81 & 5.36 & 0.113 & 0.42 \\
\hline Color & $4.67^{b}$ & $5.28^{\mathrm{ab}}$ & $6.25^{\mathrm{a}}$ & 0.167 & 0.046 \\
\hline Overall acceptability & $6.83^{\mathrm{ab}}$ & $6.58^{\mathrm{b}}$ & $7.00^{\mathrm{a}}$ & 0.016 & 0.031 \\
\hline
\end{tabular}

SEM, standard error of the mean $(n=10$, number of replicates).

${ }^{1}$ Scale $1-9$ (from $1=$ dislike extremely to $5=$ neither positive nor negative to $9=$ like extremely)

a-b Within row, means without a common superscript differ $(p>0.05)$.

of all groups, the pigs gained $880 \mathrm{~g}$ weight $/ \mathrm{d}$, ate $2.37 \mathrm{~kg}$ feed/d, had slaughter weights of $96.8 \mathrm{~kg}$ with a dressing percentage of $73.9 \%$ and a lean percentage of $59.7 \%$.

\section{Effects of purple rice on general raw meat quality}

Most physical meat quality traits, like water-holding capacity and tenderness (measured as shear force), are rather resistant to dietary interventions and are more dependent on genetics and animal treatment during slaughter (Warriss, 2010). As pigs of all groups had the same average age at slaughter and were fattened and slaughtered balanced by gender and slaughter day, no agedependent changes like crosslink formation among collagen molecules (Mayoral et al., 1999) were expected, either.

Meat color was among the few physicochemical traits which were significantly affected. Absorption of anthocyanins has been described earlier by Cao et al. (2001). However, in the present study no effect of feeding purple rice on meat redness compared to the corn diet was found, whereas the meat was unexpectedly redder with the white rice diet. Apparently, there was also no substantial transfer of the yellow pigments from the corn to the meat as the pork of the corn-fed pigs was the least yellow. The coloring agents may have accumulated in the fat stores instead, but fat color was not measured in the present study. In the cooked unprocessed loin chops, the use of purple rice compared either to corn (firmness) or to white rice (juiciness, tenderness, overall acceptability) resulted in some sensory improvements which were, however, not recovered in the processed meats products.

\section{Effect of purple rice effects on lipid-related properties of the raw meat}

Among the traits related to lipid metabolism, some were affected by feeding purple rice. These effects could be grouped into i) indications for antioxidant-type effects, ii) cholesterol modifying effects, and iii) effects on body tissue lipid content and its FA profile.

The most prominent antioxidant-like effect was the slower TBARS formation when storing raw meat from purple-rice fed pigs which, however, was prominent only on the last day of storage (day 9). This could have been the action of the anthocyanins which are also responsible for the purple rice color. Anthocyanins are known to have antioxidant potential (Nelida et al., 1998; Weisel et al., 2006). If the anthocyanins indeed were (one of) the active principles in the purple rice, they must have been at least partially absorbed from the pig's gut thus getting active in the muscle lipids of the animals investigated in the present study. Absorption could have taken place unchanged or in the form of breakdown products. The lack of changes in meat color suggests the latter. Also $\gamma$-oryzanol has antioxidant potential which was found to be ten times greater than that of vitamin E (Xu et al., 2001). Even when considering that this compound is supposed to be more concentrated in purple than in white rice (Boonsit et al., 2006), the lack of a response in TBARS to white rice as compared with the corn diet seems puzzling. Further aspects may have contributed to or prevented antioxidantlike effects when feeding purple rice instead of white rice or corn, which were, however, not analyzed in the present study. These include differences between purple and white rice in the content of other bioactive compounds present in rice, especially in the bran (Devi et al., 2007; Chotimarkon et al., 2008), like the squalene (Rohman, 2014) and the level of transfer of the active compounds or their breakdown products into the tissue and the effect.

Both active principles, the anthocyanins (Chen et al., 2006) and the $\gamma$-oryzanol, were described to be favorable with respect to plasma lipids, too. Wilson et al. (2007) found that $\gamma$-oryzanol, extracted from purple rice, can decrease very low and increase high density plasma lipoproteins. As $\gamma$-oryzanol inhibits cholesterol esterase (Rukmini and Rughuram, 1991), others found that supplementing a purple rice extract can decrease the levels of triglycerides and low-density lipoprotein associated cholesterol in plasma and liver of rats (Chen and Cheng, 
2006; Zawistowski et al., 2009). This coincided with the effects of feeding purple rice on cholesterol content of the raw loin chops, even though this only happened in relation to the white rice diet (where the cholesterol content analyzed was unexpectedly high) and not to the corn diet. Plasma cholesterol levels were concomitantly reduced in the pigs of the same experiment (Peawong et al., 2011), but this was not persistent with age of the animals and, therefore, it remains open whether it was a genuine effect. The experimental set-up did not allow separating potential effects of the anthocyanins from those of the $\gamma$-oryzanol in terms of plasma and muscle lipid metabolism of the pigs.

The IMF content (raw loin chops) was lower when feeding purple rice instead of white rice. Concomitantly, belly fat content (determined in the smoked bacon) was lower. This coincided numerically with the backfat thickness of $2.11,2.35$, and $2.17 \mathrm{~cm}$ found with the diets with corn, white rice and purple rice, respectively, as reported earlier in Peawong et al. (2011). It still remains unexplained why there was a clear difference between the two rice groups in the proportionate response of IMF (loin chops) and intermuscular fat (bacon) because this would suggest that the purple rice diet had less energy. However, all other indicators do not support this conclusion. The active principles in purple rice may, therefore, also have caused a modified lipid metabolism resulting in a reduced fat deposition in (selected) body tissues. Indeed, also the FA profile of the IMF (loin) was different with purple rice compared to that found with white rice and corn. The changes must have resulted from metabolic effects since the FA profile of the diets was quite similar. Several individual minor FA with high human-health relevance as the n- 6 and the n-3 FA were different between the purple rice diet and the other diets, or between both rice diets and the corn diet. There was a certain supply with very long-chain n-3 FA with the diets through the fishmeal (not analyzed, but the lipids of similar diets contained $0.5 \%$ to $0.6 \%$ of $22: 6 n-3$; Jaturasitha et al., 2009), but this equally in all diets.

\section{Recovery of purple rice effects in meat products}

The analytical program carried out with cured loin chops (Kassler Rippchen style) and smoked bacon was less extensive than that performed with the raw loin chops, but a series of indicators was investigated in one or both products as well. When processed, both products were treated with brine containing antioxidant substances (nitrite). This measure kept TBARS formation as low as in the raw meat in the cured loin chops this, whereas the lipids in the smoked bacon had a starting level in TBARS twice as high as that found in both types of loin chops at the end of the 9day storage period. This can be explained by the much higher fat content of the bacon and, maybe, the effect of the smoke treatment. In both meat products, different from the raw loin chops, no diet effects on TBARS level were observed, probably because the steps imposed during processing were overriding differences present in the raw meat. Like in the raw loin chops, water-holding capacity was not affected by the rice treatments in the meat products. The contents of fat and cholesterol were lower in the bacon from the pigs fed purple rice like in the raw loin chops; however, differences were only recovered in relation to the white rice diet and not to the corn diet. Other effects of purple rice found in the raw meat could not be determined at all after processing the meat. In detail, this includes the lack of change in oxidative shelf life of both products and in protein content of the bacon and the wide lack of dietcaused changes in FA profile of smoked bacon. This indicates that processing might have levelled out at least part of the differences between dietary treatments found in the raw meat. In addition, the kind of processing seems to have been decisive for the extent to which dietary treatment effects on oxidative shelf life and FA profile could be recovered afterwards. This phenomenon was demonstrated before in meat products from pigs (Khiaosa-ard et al., 2011) and poultry (Loetscher et al., 2014).

When comparing the two meat products investigated in the present study, it seems that more of the specific properties of the meat caused by feeding purple rice could be conserved in the smoked bacon, as panelists were able to discriminate smoked bacon by diet-type origin quite well, but not those of the unprocessed and the cured loin chops. The smoked bacon produced from the purple rice fed pigs was scored better in flavor, color and overall acceptability than that from the white rice diet or the corn diet. Flavor in pork is influenced by lipid-related traits like atypical FAs and oxidation. This was for instance shown by Jaturasitha et al. (2009) for pork produced from fish-oil fed pigs. Vice versa, the antioxidant effect of purple rice may, therefore, have positively affected flavor. Either this, or color, which was found in the raw loin chops to be less red and less yellow with purple rice than that of the other groups, or both eventually resulted in the high overall acceptability of the bacon prepared from the purple-rice fed pigs.

\section{CONCLUSION}

Distinct traits of meat quality from pigs fed purple rice were improved to some extent compared to that from pigs receiving white rice or corn instead, and this without impairing general meat quality. There were significant differences in several lipid related traits, but in some cases the difference was of low practical relevance with respect to its magnitude. The responses to the dietary treatments found in the two pork products investigated were mostly less pronounced than in the raw meat and were variable, depending on product. Further studies are required to show 
whether effects originate more from the specific purple anthocyanins or the $\gamma$-oryzanol or both, and how transiency and low recovery in meat products of some of the favorable effects of purple rice can be counteracted. Furthermore, the transfer rate of (breakdown products of) anthocyanins and of possible other bioactive compounds like squalene into the meat and meat products body tissues have to be quantified.

\section{CONFLICT OF INTEREST}

We certify that there is no conflict of interest with any financial organization regarding the material discussed in the manuscript.

\section{ACKNOWLEDGMENTS}

This study was financially supported by the Research Institute of Science and Technology, Chiang Mai University, Thailand as well as The National Research University under The Commission of Higher Education, Ministry of Education, Royal Thai Government.

\section{REFERENCES}

AMSA. 1995. Research Guidelines for Cookery, Sensory Evaluation and Instrumental Tenderness Measurements of Fresh Meat. American Meat Science Association. Savoy, IL, USA.

AOAC. 1996 Association of Official Analytical Chemist, Official Methods of Analysis. 15th edition. Arlington, VA, USA.

AOAC. 2005. Association of Official Analytical Chemist, Official Methods of Analysis. 18th Edition. Arlington, VA, USA.

Bohac, C. E., K. S. Rhee, H. R. Cross, and K. Ono. 1988. Assessment of methodologies for calorimetric cholesterol assay of meats. J. Food Sci. 53:1642-1644.

Boonsit, P., D. Kaladee, and P. Pongpiachan. 2006. Gamma oryzanol content in purple rice Thailand local genotypes. Agric. Sci. J. 37(Suppl.):191-194.

Cao, G., H. U. Muccitelli, C. Sánchez-Moreno, and R. L. Prior. 2001. Anthocyanins are absorbed in glycated forms in elderly women: A pharmacokinetic study. Am. J. Clin. Nutr. 73:920926.

Chen, C. W. and H. H. Cheng. 2006. A rice bran oil diet increases LDL-receptor and HMG-CoA reductase mRNA expressions and insulin sensitivity in rats with streptozotocin/nicotinamideinduced type 2 diabetes. J. Nutr. 136:1472-1476.

Chen, P. N., S. C. Chu, H. L. Chiou, W. H. Kuo, C. L. Chiang, and Y. S. Hsieh. 2006. Mulberry anthocyanins, cyanidin-3rutinoside and cyanidin-3-glucoside, exhibited an inhibitory effect on the migration and invasion of a human lung cancer cell line. Cancer Lett. 235:248-259.

Chotimarkorn, C., S. Benjakul, and N. Silalai. 2008. Antioxidant components and properties of five long-grained rice bran extracts from commercial available cultivars in Thailand. Food Chem. 111:636-641.
Council for International Organizations of Medical Sciences and the International Council for Laboratory Animal Science. 2012. International Guiding Principles for Biomedical Research Involving Animals. http://grants.nih.gov/grants/olaw/ Guiding_Principles_2012.pdf Accessed September 4, 2014.

Department of Livestock Development. 2002. Meat Processing. Division of Livestock Extension. Ministry of Agriculture and Cooperation, Bangkok, Thailand.

Devi, R. R., A. Jayalekshmy, and C. Arumughan. 2007. Antioxidant efficacy of phytochemical extracts from defatted rice bran in the bulk oil system. Food Chem. 104:658-664.

El-Sayed, M., J. Abdel-Aal, C. Young, and I. Rabalski. 2006. Anthocyanin composition in black, blue, pink, purple, and red cereal grains. J. Agric. Food Chem. 54:4696-4704.

Folch, J., M. Lees, and G. H. S. Stanley. 1957. A simple method for the isolation and purification of total lipid from animal tissue. J. Biol. Chem. 226:497-509.

Hill, F. 1989. The solubility of intramuscular collagen in meat animals of various ages. J. Food Sci. 31:161-166.

Jaturasitha, S., R. Khiaosa-ard, P. Pongpiachan, and M. Kreuzer. 2009. Early deposition of $n-3$ fatty acids from tuna oil in lean and adipose tissue of fattening pigs is mainly permanent. J. Anim. Sci. 87:693-703.

Khiaosa-ard, R., P. Chungsiriwat, N. Chommanart, M. Kreuzer, and S. Jaturasitha. 2011. Enrichment with $n-3$ fatty acid by tuna oil feeding of pigs: changes in composition and properties of bacon and different sausages as affected by the supplementation period. Can. J. Anim. Sci. 91:87-95.

Loetscher, Y., M. Kreuzer, D. Albiker, R. Stephan, and R. E. Messikommer. 2014. Effect of replacing dietary vitamin E by sage on performance and meatiness of spent hens, and the oxidative stability of sausages produced from their meat. Br. Poult. Sci. 55:576-584.

Makkar, H. P. S. 2003. Quantification of Tannins in Tree and Shrub Foliage: A Laboratory Manual. Kluwer Academic Publishers, Dordrecht, NL, USA.

Mayoral, A. I., M. Dorado, M. T. Guillén, A. Robina, J. M. Vivo, C. Vázques, and J. Ruiz. 1999. Development of meat and carcass quality characteristics in Iberian pigs reared outdoor. Meat Sci. 52:315-324.

Morrison, W. R. and L. M. Smith. 1964. Preparation of fatty acid methyl esters and dimethylacetals from lipids with boron fluoride-methanol. J. Lipid Res. 5:600-608.

Nelida, G., J. R. Ramirez-Martnez, J. O. Aldana, M. E. RamosNino, M. N. Clifford, S. Pekerar, and B. Méndez. 1998. Isolation, characterization and determination of biological activity of coffee proanthocyanidins. J. Sci. Food Agric. 77:368-372.

NRC (National Research Council). 1998. Nutrient Requirements of Swine. 10th rev. ed. National Academies Press, Washington DC, USA.

Peawong, W., P. Ratanapradit, S. Jaturasitha, T. Apichartsrungkoon, D. Karladee, and P. Pongpiachan. 2011. Effects of glutinous purple rice (Oryza sativa L.) on performance, plasma cholesterol, and carcass quality of growing-finishing pigs (in Thai). J. Agric. 27:101-112.

Pharmacopée Francaise Vigne rouge. 1996. Aid to secure the sanitary safety of health products. 10th edition. Agence Franc, Paris, France. 
Raes, K., S. De Smet, and D. Demeyer. 2001. Effect of doublemuscling in Belgian Blue young bulls on the intramuscular fatty acid composition with emphasis on conjugated linoleic acid and poly-unsaturated fatty acids. Anim. Sci. J. 73:253-260.

Rohman, A. 2014. Rice bran oil's role in health and cooking. In: Wheat and Rice in Disease Prevention and Health (Eds. R. Watson, V. Preedy, and S. Zibadi). Elsevier B.V., Amsterdam, The Netherlands. 481-490.

Rossell, J. B. 1994. Measurement of rancidity. In: Rancidity in Foods (Eds. J. C. Allen and R. J. Hamilton). Chapman \& Hall, London, UK. pp. 22-53.

Rukmini, C. and T. C. Rughuram. 1991. Nutritional and biochemical aspects of the hypolipidemic action of rice bran oil: A review. J. Am. Coll. Nutr. 10:593-601.

Teltathum, T. 2004. Effect of gamma oryzanol in purple glutinous rice bran on immune response in male mice (Mus musculus). Master thesis. Chiang Mai University, Chiang Mai, Thailand. $155 \mathrm{p}$.

Warriss, P. D. 2010. Meat Science: An Introductory Text. 2nd Edition. CAB International, Wallingford Oxfordshire, UK.
Weisel, T., M. Baum, G. Eisenbrand, H. Dietrich, F. Will, J. P. Stockis, S. Kulling, C. Ruefer, C. Johannes, and C. Janzoaski. 2006. An anthocyanin/polyphenolic-rich fruit juice reduces oxidative DNA damage and increases glutathione level in healthy probands. Biotechnol. J. 1:388-397.

Wilson, T. A., R. J. Nicolosi, B. Woolfrey, and D. Kritchevsky. 2007. Rice bran oil and oryzanol reduce plasma lipid and lipoprotein cholesterol concentrations and aortic cholesterol ester accumulation to a greater extent than ferulic acid in hypercholesterolemic hamsters. J. Nutr. Biochem. 18:105-112.

$\mathrm{Xu}, \mathrm{Z}$., N. Hua, and J. S. Godber. 2001. Antioxidant activity of tocopherols, tocotrienols, and $\gamma$-oryzanol components from rice bran against cholesterol oxidation accelerated by 2,2 'azobis(2-methylpropionamidine) dihydrochloride. J. Agric. Food Chem. 49:2077-2081.

Zawistowski, J., A. Kopec, and D. D. Kitts. 2009. Effects of black rice extract (Oryza sativa L. indica) on cholesterol levels and plasma lipid parameters in Wistar Kyoto rats. J. Funct. Foods 1:50-56. 